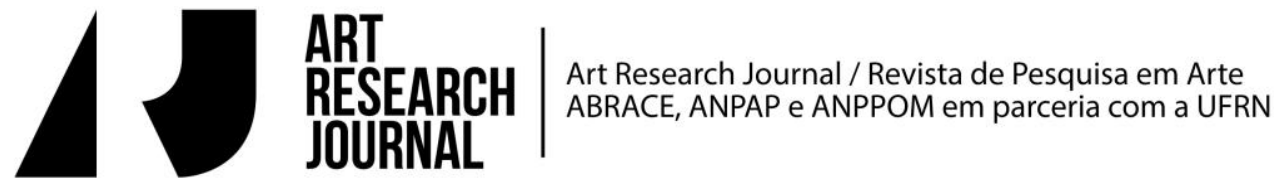

\section{Experiência e história na pesquisa em artes}

\author{
Mario Fernando Bolognesi \\ PPGA-UNESP/CNPq
}

\section{Olhares estrangeiros}

Comparativamente às idades dos homens, a pesquisa em artes, no Brasil, vive a sua infância. Essa comparação leva em conta a relativa maturidade alcançada por outras áreas de investigação, especialmente marcante a partir do experimentalismo que impulsionou as ciências modernas. No campo das ciências humanas tal avanço também é significativo e em seu interior as investigações artísticas dão os seus primeiros passos.

Em outras épocas as artes também mereceram investigação. Elas foram interpretadas sob o prisma da filosofia ou da teologia, procurando entender 0 fenômeno artístico como parte integrante de sistemas complexos de consolidação do pensamento. Não era a arte em si que estava em questão, mas sim o seu enquadramento em um conjunto maior de ideias, formando uma espécie de totalidade a visualizar o lugar de cada uma das atividades humanas, as práticas, as teoréticas e as poéticas no conjunto geral dos sistemas filosóficos e/ou teológicos. Tratavam-se, portanto, de filosofias da arte e não da investigação artística propriamente dita. Inclusive a Estética, enquanto disciplina filosófica, adentrou o panorama do conhecimento filosófico tardiamente e, mesmo assim, com o pressuposto de investigar o belo artístico, tendo por base o juízo de gosto.

Em outras palavras, a constituição das artes como objeto e problema específicos de investigação científica é fenômeno relativamente recente. No âmbito das ciências humanas ela é a filha caçula. A implicação imediata dessa infância é a ausência de 
teorias e métodos consolidados para subsidiar tal ação. Outros campos de saber das ciências humanas já têm corpos teóricos e metodológicos sustentáveis.

Os pesquisadores em artes recorrem a teorias "estrangeiras", adaptando-as, mutilando-as, mas também ampliando-as e modificando sua abrangência e seu campo de ação. Em outro ângulo, teorias concebidas para abordarem outros objetos são forçadas ao exílio, com vistas a socorrer a infância dos estudos em artes.

As ciências sociais, por exemplo, investigaram, experimentaram e puseram à prova várias teorias científicas. Os autores clássicos nessas ciências (Durkheim, Marx e Weber) consolidaram teorias e métodos específicos que norteiam a construção de conhecimentos. Igual perspectiva verifica-se nos estudos literários, nos estudos lingüísticos, na História e nas diversas ciências que alcançaram alguma solidez epistemológica.

Salvo engano, os estudos em artes não produziram teorias específicas para a investigação. Os pesquisadores buscam suporte em teorias forjadas para abordar outros objetos, que não os artísticos. Assim, é comum que teorias literárias, por exemplo, sustentem alguns estudos em artes, sejam elas fundamentadas na lingüística, na semiologia, na crítica genética ou na história da literatura. Provavelmente, essas sejam as recorrências mais evidentes nas pesquisas em artes. Mas não são, certamente, as únicas. Outras investidas solicitam outros olhares teóricos, a exemplo das já referidas ciências sociais (incluindo a Política, a Antropologia, a Etnografia e a Etnologia), as teorias da história, as filosóficas, as psicológicas, as pedagógicas e as econômicas.

Evidentemente, um historiador das ciências apontaria, de imediato, uma infinidade de exemplos em que determinado campo de investigação, para dar seus primeiros passos, buscou paradigmas em outras ciências. Esse foi e ainda é um processo corriqueiro, perfeitamente reconhecível em todas as ciências. Essa história não ocorreu por intermédio de solavancos e radicais rupturas. A Filosofia, ao surgir, incorporou estruturas do pensamento mítico; a Química é devedora da Alquimia. Os exemplos se multiplicam. Mas, o mesmo historiador também apontaria diversos momentos em que modelos teóricos e metodológicos específicos consolidam uma nova disciplina científica. Este fenômeno esteve em efervescência a partir do empirismo, que impulsionou, com o tempo, o desligamento de várias disciplinas científicas, antes abrigadas sob o manto imenso da Filosofia. As especificidades científicas se consolidaram e, juntamente 
com a Filosofia, particularmente a Estética, subsidiam a jovem e promissora pesquisa em artes.

Esse empréstimo certamente contribui para a multiplicidade de olhares a respeito do fenômeno artístico. Mas resta sempre presente a sensação do incompleto, da ausência daquele elemento intrínseco e fundante que viria a selar as relações de contradição (necessárias e implícitas) entre, pelo menos, o fazer artístico, a obra acabada e sua compreensão no âmbito da produção de conhecimento.

Caberia, contudo, indagar se essa ausência de teorias específicas e amalgamadas aos estudos em artes não seria apenas uma sensação sem maiores consequências, uma manifestação egocêntrica que reconhece sua impotência em criar teorias e métodos que contribuam para abordar o fenômeno artístico em sua complexidade e, com isso, estabelecer patamares razoavelmente sólidos para um conhecimento universal. Afinal, as teorias almejam e se postam como legitimadoras da universalidade do conhecimento.

\section{0 cerco}

Pesquisar é cercar algo e investigá-lo. É o que dizem os dicionários. Em língua italiana o termo e seu sentido tornam-se evidentes: ricerca. O "algo" aqui referido pode ser uma obra pronta e acabada, um processo criativo, um problema instigador de pesquisa, um fenômeno e sua fortuna crítica, enfim, tudo aquilo que possa ser tomado como objeto de investigação.

O sujeito que cerca algo pode se colocar dentro ou fora do cercado. Isso não impede a migração, temporária ou definitiva, de um lugar para outro. Estar dentro impulsiona um ato de experiência intrínseca ao objeto investigado, que, em artes, pode ser um processo criativo. Nesse caso, o pesquisador e o artista fundem-se em um único agente e o processo de migração entre o dentro e o fora é ato que se reproduz frequentemente. Estar dentro, no entanto, não significa investigar exclusivamente os caminhos da criação artística do sujeito que cercou um objeto. A experiência extrapola os limites daquilo que é pessoal e intransferível. Quando o sujeito se coloca do lado de fora, ele assume, conscientemente, um papel distanciado, que se aproxima da atitude "clássica" do pesquisador, equivalente ao trabalho investigativo do historiador, por exemplo. A referência, aqui, é a do historiador que investiga processos históricos passados, nos quais ele não agiu. 
O ato de investigar demanda, de imediato, a delimitação de um objeto, de um problema ou de um conjunto de fenômenos. Delimitar algo é estabelecer seus contornos para que ele possa se distinguir daquilo que o rodeia; é, ao mesmo tempo, ato de se destacar dentre a multiplicidade e, com isso, alcançar uma identidade, uma particularidade que o torna reconhecível.

Cercar algo com vistas a investigá-lo é similar ao ato de cercar uma porção de terra para afirmar a posse e a propriedade. O sujeito que procedeu à investigação transforma-se em autor dessa descoberta, isto é, proprietário, especialmente quando ela redunda em tecnologias que se voltam à vida prática. As similaridades entre o investigador e o proprietário não cessam aí: ambos fazem com que suas "posses" se diferenciem das demais e, com isso, galgam outros patamares na escala do reconhecimento social.

A imagem/metáfora do cercar traz consigo os principais quesitos do pesquisar: delimitação do objeto ou de um problema; emprego de um método e de princípios teóricos que norteiam o cercar e possibilitam a investida em terreno desconhecido e inóspito. Não se cerca algo, com vistas a conhecê-lo, a partir do nada. Experiências, conhecimentos anteriores e teorias induzem a escolha do objeto a ser investigado. Afinal, teoria tem o sentido de olhar através de e se liga à idéia do olhar de alguém sobre algo. Com a mesma matriz etimológica, teatro é o lugar de onde se vê, um espaço que organiza o olhar.

Uma vez eleito, o objeto do cerco passa a ser visualizado a partir dos paradigmas de tempo e espaço. Ambos induzem ao reconhecimento do objeto ou do problema a ser investigado em uma história e em uma experiência social e cultural. A história incide tanto no próprio objeto quanto na história do conhecimento que a seu respeito se produziu.

\section{O objeto na história}

Situar o objeto no tempo e na história não deve ser lido com o intuito de se conhecer sua arché. Se esse intuito prevalecesse teríamos, fatalmente, em todas as investigações em artes cênicas, o retorno ao teatro grego, caso a investigação se circunscrevesse no âmbito da cultura Ocidental. Não se trata, pois, de buscar as origens, embora, para alguns casos, essa busca seja imprescindível.

A dimensão temporal é critério relevante quando possibilita a compreensão sincrônica e diacrônica do objeto, quando o apresenta como resultado de 
situações históricas alojadas no jogo complexo e contraditório das práticas sociais e culturais. Em outras palavras, não basta saber apenas o com e onde tal objeto se forjou: o por quê? e o para quê? são perguntas necessárias. Para as artes, o tempo histórico tem pertinência porque se associa a espaços simbólicos.

A compreensão histórica problematiza e relativiza a ideia do novo, da obra e sua particularidade inovadora, do criador como gênio e visionário. Esses aspectos mentais forjados e alimentados em tempos românticos ainda perambulam e agem como fantasmas a mascarar o real campo de forças, inserção e atuação do fazer artístico. A ideologia do gênio criador provoca igualmente a distância entre produtores e apreciadores, com significativas rupturas entre ambas as esferas: ela privilegia um sujeito e sua genialidade reforça a inferioridade dos demais.

O jogo de forças que interfere nos processos criativos, e dos quais as obras são resultado e expressão, está escamoteado na visão do grande criador. Nas artes da cena a concretude do fazer é resultado de processos contraditórios em que se defrontam projetos, pessoas e possibilidades concretas de efetivação. Os projetos são manifestações da mais intrínseca subjetividade, que revelam leituras do momento histórico, de situações de vida e de mentalidade de determinada sociedade ou estrato social, de projeções de futuro, enfim, eles conjugam a leitura do "que é", associada à utopia do "como poderia ser". Os envolvidos nos projetos depositam neles suas expectativas, mas as equacionam com as condições reais da existência e as possibilidades concretas de realização, que envolvem recursos financeiros e materiais, condicionados a investimentos, prazos, produtores, divulgadores e muitos outros profissionais. Em suma, a imaterialidade dos sentidos propostos pela obra e sua criação dialoga em campo de perpétuo conflito com as condições materiais de sua realização e, portanto, não é ato exclusivo da vontade que emana do gênio criador. O gênio quer se distanciar da concretude da história e das práticas sociais e culturais, quando a incidência da ideia do belo, desprovida de materialidade, termina por prevalecer.

\section{Sujeito e conhecimento}

O conhecimento em artes não se pauta pela descoberta de verdades, que se faz cumulativa e, concomitantemente, renovadora, quando a última investigação suplanta as anteriores. A mais recente investigação a respeito da mimese, por exemplo, não é a última verdade sobre ela e nem suplanta as ponderações elaboradas na mais longínqua Antiguidade. A arte como imitação é assunto que 
atravessa os séculos e Platão e Aristóteles não são nem superiores nem inferiores às atuais investidas da estética do teatro nesse tema. A pesquisa em arte produz conhecimento que tanto pode ser contraposição a outros, ou expansão do raio de interpretações, como pode ser complementar, ou mesmo reiterativo e, neste caso, termina por ser uma exemplificação, um reforço de algo sabido. O tempo histórico e o espaço social e cultural são balizadores dos saberes, que não são excludentes

Nesse aspecto, a pesquisa em artes e a produção e/ou criação artística se aproximam. Não se diz que uma obra artística seja portadora de verdades. As criações artísticas contemporâneas não estão acima ou abaixo daquelas produzidas em épocas remotas. Seria exercício idiossincrático o uso, para as artes, dos critérios válidos às ciências experimentais. A história da obra é alicerce para sua consagração, assim como os espaços que a tornam significativa.

O ponto de convergência entre a criação artística e o trabalho investigativo é o sujeito. Nesses termos, o início da pesquisa - o cercar um objeto - nada mais é do que o cercar uma determinada ação humana, que interfere na história, e dela passa a fazer parte, em espaços e situações concretas de produção, realização e manifestação. Sujeito e objeto, na produção das artes e na pesquisa em artes, terminam por se unificar e configuram um único paradigma: ação humana para a criação e produção de conhecimento e de sentidos.

A subjetividade desponta, então, como elemento sustentador da singularidade das pesquisas em artes. Concomitantemente, ela aproxima a pesquisa da produção e criação, pois ambas têm os sujeitos e suas ações como mediadores do ato artístico e de sua pesquisa. Para se completar, a ação artística, que emana de um ou mais sujeitos, direciona-se a outros sujeitos. No encontro e na relação intersubjetiva a arte e sua prática se efetivam como experiência. Esta experiência é dependente de relações materiais e, a partir delas, estabelecem-se sentidos imateriais que se projetam para o campo da prática cultural, por meio da consolidação e/ou superação de ideias, de proposições éticas, morais e políticas, que se projetam no jogo social.

$\mathrm{Na}$ pesquisa em artes, a experiência torna-se elemento diferenciador, comparativamente à investigação em outros campos do saber. Essa experiência não ocorre sob o prisma do distanciamento e da ruptura epistêmica entre o sujeito cognoscente e o objeto cognoscível. Ao contrário, ela é parte integrante, 
ela é o próprio sujeito, especialmente quando se admite o trabalho criativo e a investigação do conhecimento em artes como componentes intrínsecos à subjetividade, pois ambas as ações se identificam em seus processos de subjetivação. Em artes, as produções de obras e de conhecimento não se alienam dos sujeitos que a elas se dedicam.

\section{Material e imaterial}

A pesquisa em artes (assim como em outras áreas) se orienta sob três grandes campos: o descritivo, o analítico, e o interpretativo. Para o primeiro deles deve prevalecer uma postura distanciada e objetiva do pesquisador em sua investigação. A apresentação do objeto - a descrição de sua natureza, de suas qualidades e quantidades, de sua contextualização no tempo e sua inserção no espaço - deve ser ato da mais estreita objetividade. A matéria manifesta-se na obra e sua corporeidade, no texto escrito, na partitura, nos desenhos, croquis, gravações, vídeos, nos relatos, entrevistas e diários de campo, nos textos de imprensa e na fortuna crítica. Para os demais campos, o sujeito do conhecimento faz prevalecer seu instrumental teórico e metodológico. O campo interpretativo aprofunda a investigação em seus aspectos imateriais e simbólicos. Como o próprio nome indica, ele se aproxima do especulativo e demanda ato de articulação do pensamento. $\mathrm{O}$ analítico age como intermediário, quando matéria e imaterialidade têm presenças garantidas e a investigação prima pelo ato comparativo, a partir dos parâmetros de tempo e espaço.

Para as artes plásticas e visuais a materialidade alcança maior presença, uma vez que se dá fenomenicamente em sua visibilidade, por meio de cores, traços, formas e ações performáticas, por exemplo. Com isso, o parâmetro do tempo pode ser operado cronologicamente. Essa operação é possível quando a obra não se desfaz no tempo e na experiência do presente. Quando se tratar de situações visuais em performance, que buscam a inserção perceptiva do público e que ocorrem no momento presente, tal experiência e suas pesquisas enfrentam os mesmos dilemas epistemológicos das artes espetaculares, tais como a música, a dança e o teatro, desde que tomados em sua dimensão presencial.

Para as artes que envolvem o espetacular, as matérias sonoras, corporais e visuais manifestam-se em presença, no aqui e agora. Elas são atos de temporalidade demarcada, que envolvem a relação direta entre artistas, obras e público, de caráter transitório e efêmero, cuja repetição plena é praticamente 
impossível. A implicação imediata de tal constatação é que, na radicalidade, não é possível estudar-se o teatro, a dança, a música e as artes performativas ocorridas no passado.

As restrições do aqui $e$ agora postas às pesquisas em artes, a certificação dos limites materiais leva em conta que o fenômeno da arte não pode prescindir do público apreciador e receptor, individual ou coletivamente. O avanço tecnológico propicia mecanismos os mais sofisticados para o registro do som. Eles ampliam as possibilidades empíricas e materiais da pesquisa. Contudo, não alcançaram ainda a totalidade do fenômeno no ato presencial, na conjunção da performance com a presença do público.

A música, por exemplo, pode deixar de lado o ato em presença e ater-se tão somente à exposição, análise e interpretação da matéria musical, tal como ela dá nos registros escritos e sonoros. A notação e escritura musicais alcançam maior aproximação com o evento sonoro. Elas conseguiram desenvolver uma linguagem codificada que registra instrumentação, tonalidade, modalidade, intensidade, andamento, altura, articulação, fraseado, tipos de compasso, ritmo, movimento e texto, para o caso de obras cantadas. Mas, mesmo próxima do som produzido, a escrita e a linguagem que almejam à reprodução a mais fiel possível, não consegue registrar o ruído e o erro que ocorrem involuntariamente no ato da execução musical, com a presença do público. De resto, a escrita da música é, no limite, código de escrita que se almeja fiel e que necessita se transformar em sonoridades na execução musical propriamente dita, e esta prevê necessariamente a ação do público no ato performático. O registro sonoro por meio de tecnologias de gravação e reprodução amplia o leque de ação do pesquisador. Mas, mesmo assim, a abordagem da música no passado ressentese da ausência dos imprevistos e percalços de uma arte que se faz em presença, no concerto, no show, no recital etc.

Idêntico problema se estende às artes cênicas. As formas de registros da cena transferem, em primeiro lugar, o ato cênico para o âmbito da escrita, seja ela uma descrição, um roteiro, uma peça, enfim, uma obra dramatúrgica. Os desenhos e croquis de cenários e figurinos, bem como os mapas de luz, são registros visuais estáticos. A filmagem estende o registro para o trabalho dos atores e para a encenação. De qualquer maneira, as matérias das artes cênicas disponíveis ao pesquisador são textos, desenhos, croquis, mapas e vídeo. Todos 
eles prescindem do aqui e agora. A exposição do fenômeno, sua análise e interpretação terminam desprovidas das relações ritualísticas e coletivas que se dão no presente.

As artes espetaculares apresentam impasses epistemológicos para a abordagem de fenômenos no passado. A abordagem de obras e atos artísticos acontecidos baseia-se em códigos e linguagens que se voltam ao registro parcial, pois estes não contemplam a totalidade do fenômeno. Recorrer à partitura, ao disco, ao vídeo e ao texto dramatúrgico implica em reconhecer os limites de tais registros e, com isso, reconhecer a parcialidade do estudo das artes que se efetivam no presente.

O ato presencial da música, das artes da cena e também das visuais estende-se à apreciação, à recepção, à contemplação, à participação do público, isto é, à experiência estética que congrega o criador, a criação e a recriação advinda da leitura e/ou leituras que emanam do público, dos críticos e dos comentadores. No atual estágio das pesquisas em artes, no Brasil, salvo maior equívoco, as investigações de linguagens estabelecem um tímido diálogo com a experiência estética mais ampla. As pesquisas no campo da recepção, por seu turno, não se aprofundam no emaranhado dos processos criativos e nas especificidades das linguagens artísticas.

Os temas relativos à projeção estética mais ampla apontam que o objeto artístico apresenta características que ultrapassam o campo exclusivo da matéria, embora dele seja dependente. Trata-se do alcance imaterial da obra e de seus processos, que opera no âmbito dos sentidos provocados pelo autor e pela obra, absorvidos e difundidos pela experiência estética. Os estudos em artes, nesse aspecto, se projetam para além das minúcias de linguagens e alcançam o terreno da projeção e da repercussão coletivas, reconciliando o tempo e o espaço.

Projetar as pesquisas em artes para os sentidos culturais e sociais que os objetos investigados almejam e provocam, permite a aproximação das pertinências e singularidades do texto (das linguagens específicas e de sua materialidade) com o contexto em que tal matéria se efetiva. Os espaços sociais e culturais em que as obras e as experiências artísticas se efetivam são carregados de significação.

$\mathrm{Na}$ imaterialidade distinguem-se processos, públicos, experiências e dimensão social. Obras são constituídas em parcerias, voltadas para práticas coletivas; 
outras são postas em templos das artes, com vistas a preservar a distância entre o artista e o apreciador, em ato de contemplação; outras enfatizam os aspectos processuais do ato educativo e formativo; outras (a maioria) são fabricadas em série, em processo altamente industrializado, com vistas ao consumo; outras se dirigem ao lazer e à recreação. Cada uma dessas possibilidades corresponde a processos materiais distintos de práticas sociais, que podem ser artesanais, comerciais ou industriais. No tocante ao destino e às práticas culturais, podem ser individuais, coletivos, religiosos, ritualísticos, contemplativos e de entretenimento. Essas instâncias, com muita frequência se mesclam.

\section{Experiência e singularidade}

É conhecida a reflexão de Walter Benjamin (1987) acerca da pobreza de experiência na época contemporânea. O desenvolvimento monstruoso da técnica é a razão de tal indigência. A miséria atual se manifesta na dissociação dos sujeitos com as ideias e o conjunto do patrimônio cultural, que só teria valor significativo se estivesse amalgamado a nós por meio da experiência. A percepção de Benjamin direciona-se à humanidade como um todo. A tendência é dominante e hegemônica, mas não é única. Nichos de oposição, de rebeldia e de exercício do utópico permanecem vivos.

O avanço da técnica trouxe inúmeras mudanças e transformações do e no cotidiano, ao lado da abundância de bens materiais direcionados ao consumo. Sofisticou também as formas e modos de produção e trabalho, informatizou espaços individuais e coletivos, interferindo nas relações intersubjetivas. Quanto maior a sensação de felicidade proporcionada pelos bens disponíveis, maior a rendição à sociedade de consumo, que suplanta a noção de cidadão para impor a de consumidor. O indivíduo e a individualidade se perdem em meio aos produtos, a ponto de ofuscar as marcas e características dos sujeitos em meio à profusão desconcertante das mercadorias.

Em uma época dominada pelo mercado, tanto das coisas, como das consciências e da subjetividade, a arte, sua criação e sua investigação, quando não se voltam à reificação proposta pelo mercado, despontam como elementos singulares de entrelaçamento de sujeitos. A intersubjetividade é garantidora da experiência e as artes são terrenos ainda férteis para sua proliferação. A qualidade dessa experiência se consolida na medida em que a criação evoca a liberdade como 
ideal supremo. Com isso, elas podem operar a emancipação da sensibilidade, da imaginação e da razão crítica.

A experiência na criação pode se transferir à pesquisa em artes, tornando-a sui generis e, salvo maiores equívocos, este parece ser um elemento particular a pulsar a favor da especificidade dos estudos em artes. O conhecimento prático e sensível do artista, quando transferido e acionado pelo pesquisador, facilita a abordagem dos enlaces e desafios poéticos da criação. A experiência de si ajuda a compreender a do outro.

Quando o pesquisador e o artista se fundem, a sensibilidade, a imaginação e a razão caminham juntas. Mas, ponderações são necessárias: esse amálgama pode se transformar em pura aparência e revelar seus equívocos quando se opta por investigar a si mesmo e seus processos criativos. Nesse caso, o sujeito torna-se objeto de exposição e a razão crítica tende a ser posta de lado. Essa postura egocêntrica se acentua ainda mais quando a exposição e o suposto estudo de si vêm desprovidos de uma inserção histórica. Abandonam-se, assim, os parâmetros do tempo e do espaço. A inserção histórica e o espaço de realização do simbólico são preteridos e o novo e intruso inquilino da investigação termina se revelando imagem deturpada de um eu supostamente soberano e autosuficiente. A experiência se perde, pois não se propõe a se realizar no coletivo e no intersubjetivo. Isolada, a consciência do artista e pesquisador que se toma como objeto de exposição manifesta sua fragilidade e, ao mesmo tempo, associa-se aos bens consumíveis e ligeiros do mercado. Essa consciência, inflacionada e autoreferida, abandona o sentido ulterior e coletivo da experiência: torna-se coisa em meio a tantas outras coisas.

Não obstante o risco de esvaziamento e deterioração, a criação e a pesquisa em artes podem superar o estágio de letargia da exposição sumária e arbitrária de si. Um dos caminhos é a retomada do dialogismo e a adoção da atitude concomitante de aprendiz e mestre para com outras realidades de criação e pesquisa. Essa transferência e contato de saberes, regidos por uma sadia contaminação de experiências coletivas, fazem da pesquisa em artes algo diferencial e único. 


\section{Ao final, uma ficção}

Uma estória ficcional pode refrescar as ideias aqui postas e encaminhar, intuitiva e perceptivelmente, algumas considerações.

Averróis, em Córdoba, tinha diante de si a Poética, de Aristóteles, e, segundo Jorge Luis Borges, por desconhecer a língua original do texto, não conseguia encontrar palavras adequadas para traduzir dois termos: tragédia e comédia.

Catorze séculos separavam Averróis de sua fonte. Mais do que os séculos, culturas, religiões, línguas distintas atormentavam o médico árabe. FaltavamIhe, portanto, vivência cultural, conhecimento linguístico e experiência religiosa diversa daquela apregoada pelo Alcorão.

No conto em questão (La Busca de Averroes, de Borges) Averróis, em seu trabalho, encontra-se distanciado das coisas e afazeres terrenos e cotidianos: ele está sempre em um plano topográfico superior, algo que o senso comum designaria como a "torre de marfim". Ao traduzir Aristóteles, se debatendo com suas dificuldades e limites, ele especulava a respeito do que poderia ter sido a experiência ateniense da tragédia e da comédia. Punham-se ao pensador árabe dois níveis de dificuldade: um primeiro, relativo aos fragmentos do texto aristotélico e as dificuldades com a língua; e um outro, o desconhecimento da experiência social e cultural do teatro em Atenas. Portanto, faltavam-Ihes elementos empíricos, experienciais, linguísticos e históricos.

Como foi solucionado o dilema de Averróis? Naquele mesmo dia ele jantaria na casa do alcoranista Farach. Dentre os presentes, estava à mesa o viajante Abulcásin Al Ashari, que regressara do Marrocos. A conversa corria entre os convivas até o momento em que Abulcásin narra um episódio envolvendo uma representação espetacular. Mercadores muçulmanos de Sin Kalan conduziram Abulcásin a uma "casa de madeira pintada", na qual "viviam muitas pessoas". A casa parecia ter um "quarto único", cercado de "armários ou sacadas", umas sobre as outras. As pessoas comiam e bebiam em todas essas "cavidades", assim como no chão e em um terraço, onde alguns "tocavam tambor e alaúde". Outras quinze ou vinte pessoas, que portavam máscaras vermelhas, rezavam, cantavam, dialogavam; se faziam de encarceradas, sem que se vissem as grades; cavalgavam cavalos invisíveis e imaginários; lutavam, morriam e no momento seguinte estavam em pé. E não estavam loucos, assegurou Abulcásin: 
estavam - nos dizeres de um dos mercadores - "figurando uma história". Abulcásin dirigiu-se aos convidados de Farach e sentenciou: eles "mostravam" uma história, ao invés de "contá-la".

A precária descrição de Abulcásin forneceu pistas para a resolução do dilema de Averróis: a experiência preencheu, ainda que parcialmente, as lacunas históricas, sociais e culturais da investigação especulativa do filósofo árabe. A experiência de Abulcásin não foi suficiente para assegurar a universalidade do conhecimento, mas aguçou a percepção que faltava ao processo especulativo de Averróis.

No tocante às artes, na pesquisa e em sua criação, Averróis e Abulcásin são aparências à primeira vista diversas e opostas de um fenômeno uno. Vistos amiúde, eles se complementam. O conhecimento prático dos sujeitos criadores e dos pesquisadores, aliado à universalidade da história, à experiência e prática das artes em ato de presença compõem o quadro simbólico geral no qual as artes e seus conhecimentos se inscrevem.

\section{Referências}

BENJAMIN, Walter. Experiência e Pobreza. In: Obras escolhidas. Vol. 1. Magia e técnica, arte e política. Ensaios sobre literatura e história da cultura. Prefácio de Jeanne Marie Gagnebin. São Paulo: Brasiliense, 1987, p. 114-119.

BORGES, Jorge Luis. La Busca de Averroes. In: Prosa Completa. Vol. 2. Barcelona: Editorial Bruguera, 1980, p. 69-76. 